\title{
Students' Perception toward Unwillingness to Participate in EFL Classroom
}

\author{
Meicy Intan Sari ${ }^{1}$, Anisha Ayu Anindya ${ }^{2}$, Mochammad M Romadon ${ }^{3}$, Bambang Widi Pratolo ${ }^{4}$ \\ \{mochammadmuchlisromadon@gmail.com\} \\ Magister of English Education, Universitas Ahmad Dahlan, Indonesia
}

\begin{abstract}
The importance of foreign language is required in this globalization era. English as an international language is a necessary language that has to be possessed by students and professionals. In fact, students might face difficulties on mastering the language. This resulted on students' willingness to participate the learning. This research aimed to provide a depiction of students' perceptions toward unwillingness to participate in the English classroom. The researcher uses a qualitative method to describe the data. The subject of this research belongs to EFL graduate students at Universitas Ahmad Dahlan, especially the first semester students in English education department. The result showed that students often reluctant to take part in the EFL classroom due to various matters such as linguistic factors, psycholinguistic factors, socio-cultural factors, and also institutional factors.
\end{abstract}

Keywords: Student Unwillingness, Student Partipation, Speaking, and EFL student` perception

\section{Introduction}

In this globalization era, English is an essential language that has to be possessed by students and professionals. In Indonesia, English is instructed as a foreign language. English communication has become a core skill that should be developed in all academic contexts [1]. The common question that arises from anybody who wants to know someone's ability in a foreign language is whether he/she can speak English well or not. However, EFL (English as Foreign Language) students typically have little chances to connect with people in English due to the lack of practical English practicing contexts, not to mention getting input from others to create reflections [2]. So, fluent in English is required by people to communicate with others. However, to get fluent in English, the EFL students have to study at some levels, from beginner, intermediate, and so on. In line with this, in such programs, the significance of English language learning lies not only in the role of language as one of the primary objectives, but also in its impact on the comprehension of the subject matter delivered in the language[3].

In teaching-learning process, students are being asked to be able to master all skills of English. In fact, not all students can learn English as well as others can do. Some students in the classroom even less enthusiastic in English teaching-learning process. Besides, the teaching methods will also affect student's ability in learning English. Thus, the researcher is curious about other factors that can affect the willingness of EFL students to participate in English teaching-learning classroom. 
To produce and perform compelling, coherent, and critical English skills, communication during learning time and process play a huge role toward EFL students. Emphasize the substance of conversation as students' ability to express themselves in English inside and outside the classroom is a success indicator to English teaching and learning. Moreover, researchers from other studies MacIntyre, Clement, Dornyei \& Noels described the willingness to communicate as "a state of readiness to arrive a talk at a specific time with a particular individual or people utilizing a second language or a foreign language." [4]. With a big willingness to communicate, learners are searching for ways to use the language and have more language practice than students who are less willing to communicate [5]. In EFL (English as a foreign language) environments, where students are often demotivated to use English because of the ever-present reality that their classmates typically communicate in the same native language, the perceived importance of communication when considering Willingness to Communicate, while it is commonly thought to be important for success in improving communicative competence in second language interaction[6].Concisely, the willingness to communicate assists EFL students to inform and enhance their English skills.

Moreover, the study of unwillingness participation has been investigated recently by some researchers who interest to research about students' reticence to participate in English class and another researcher has already conducted a study of problems and difficulties faced by students in participating in English classroom. The research by Savaşçi aims to highlight the reasons for reluctance in EFL oral communication classes and the perspectives of learners on this topic [7]. In a Turkish EFL environment, the researcher tries to find out the reasons for reluctance among the students who attend English oral communication courses. A similar study also investigated speaking obstacles faced by the students [8]. The study focused on the difficulties and affected factors faced by English department students of Syiah Kuala University and the efforts that students made to overcome their speaking problems. The result showed that the most problems faced by the students are less confident, lack of vocabulary, low participation in classroom activities, and difficulties in expressing the sentences.

Moreover, another finding has revealed that the difficulties faced by the students are due to fear of making a mistake, anxiety, shyness, and lack of confidence and the study was conducted by Nakhalah at Al Quds Open University [9]. He got the data using interview to investigate the speaking difficulties and causes of such problems of study speaking. A similar investigate was conducted by Mofareh, this section investigates the weak language skills of students of the English language, particularly in terms of their conversational skills and/or ability to achieve the required fluency levels in either the classroom or public sphere[10]. The several factors that directly influence the success of students in fluent English include the fear of making mistakes [11]. The similar result found that $78 \%$ of learners like English as a subject, but $90 \%$ of learners were afraid to talk because of fear of being wrong, shyness, and humor [12]. The other research about students' reflection to participate English language oral class. This aims to define the important aspects that inspire or demotivate the engagement of students in an English classroom. In schools, some students are still hesitant. These students' actions can be understood as having insufficient interest in the practice, thereby leading to unwillingness to interact[13].

From those previous studies, the researcher found that most of EFL post graduate students faced obstacles in English classroom subjects which is caused by psychological and linguistics problems. Relating to this, the researcher is interested on conducting the same research that aimed at exploring the barriers of students' participation in English classrooms encountered by the first-semester students of English education department at Universitas Ahmad Dahlan. 


\section{Literature Review}

\subsection{English as Foreign Language}

EFL is an abbreviation of 'English as a Foreign Language'. EFL is described here as a language used only in an EFL classroom setting by non-native English speakers learning English [14]. This program helped 16 years and older students to increase their English. EFL program provides plentiful options based on the student's English ability, the purpose of the study that they wanted, a program that has been offered by the involved institution, and the intensity of the program. EFL program consists of Cambridge Skill for Life, EFL Intensive, EFL Part-Time, and Preparation for IELTS. EFL program can take place from a few weeks to 10 weeks, and even 30 weeks depends on the student's tier and plan. Also, there is a part-time and full- time option. The class consists of 10 to 22 students. The students will learn from inclass practice, assignment, and personal study.

\subsection{EFL Programme}

Depends on the level of study and needs, there are several EFL programs like English for Specific Purpose (ESP), Academic English, and English for Business. a) General English - This program aimed to increase English fluency, but not for academic purposes, just for in general English. The primary purpose of the EFL program is to enhance speaking and listening skill. Learning a foreign language is important at all levels of education [15]. Aside from learning English, students received elective subjects. b) Business English - This program aimed for professional or university graduates to hone their English abilities before entering the workplace. This program is shorter in terms of duration, but more intensive, and focused on the business term. c) Academic English - This program is aimed for students that wish to continue their study to a higher education level so that this program only focused on academic English, like how to write a paper, listening to lecture, and other academic expertise.

\subsection{Student Learning Interest}

To simplifying the understanding of learning interest, first, we should analyze attention and learning. Interest means self-tendency toward something. Investment is a relative attribute that stays inside someone. On the contrary, without interest, someone will not be able to do what he wants. Whereas in term has been put forward by experts, one of them were stated by Fryer, Luke, Andrew, Kaori, Mark \& Andrew that Interest is generally recognized as important both for the initiation of learning and persistence in it. Interest is perhaps best represented as a willingness to rejoin [16].

Sulaiman; Ramli \& Kurniawan explain that interest is "a motive that causes an individual to relate to something that attracts them actively [17]. however, it concluded that interest is someone tendency towards the object or some favored activity with pleasure, being care, and exercise to react. Interest in particular areas of learning is both a means of formal education and a significant result [18].Study achievement is a result obtained by the student through various studying processes to learn something that not yet known, and through learning, they could know, understand, and comprehend better. Study achievement is a result that has been given by the teacher to the student with a specific period as a learning result. Study achievement as 
curiosity satisfier. This is based as an assumption that psychology expert usually stated that it is a curiosity tendency and it is humans basic needs, including children needs in an education program [19].

Student achievement level, in general, can be observed from student accomplishment (mastery) to learning subject. If the subject of the study gets less than $65 \%$ of students' understanding, then the student success percentage will likely be reduced .As a general understanding, there are lots of factors that influence study achievement as; intelligence, interest (motivation), concentration, physical health, ambition and determination, environment, learning method, equipment, and negative traits.

A safe and disciplined school environment, optimistic and high hopes from school members, school sanity, and student-centered activity can increase student passion for studying [9]. Various factors influence consider achievement as (1) External and instrumental factors, and the environment consists of nature and society. Helpful consists of curriculum, program, tools, facility, and teachers, and (2) internal factors consist of physiology and psychology. Psychology consists of a student's intelligence, interest, motivation, and cognitive skill

It can be concluded that students' behavior when following the learning process can indicate a student's interest in the subject, and otherwise, they are not interested in the topic. Student interest is one of a desire to study sign. willingness to consider is a tendency to pay attention and remembering continuously, want to study has a close connection to pleasant feeling, because of that, it can be said that desire to explore has occurred because friendly atmosphere toward something, person that interest to study to some subject means they are feeling pleasure to learn [12].

\subsection{Interest Indicator.}

\subsubsection{Attention}

Attention plays an important role in the following activity well, and this can affect student interest in the study. According to Yun., Shin, Kim, Jang, Ha, \& Yu, attention is more or less awareness that accompanies some activity(ability to focus in class)[20]. Then Parry, Roux, \& Bantjes aid that attention is energy concentration or some spirit power to a certain object or awareness utilization to accompany a certain activity[21].

Activity that accompanied by intense attention will be more successful and leads to higher achievement. Therefore, as a teacher have to make an effort to attract pupil attention, so they have an interest in the subject. A person that putting interest in certain activities will give more attention. They will not hesitate to put more time and effort into that activity. Because of that, a student that has an interest to put more time and effort into that activity. Because of that, a student that has an interest in a particular subject will always try hard to get a good grade through learning.

\subsubsection{Feeling}

Students feeling toward the subject that is taught is a crucial element. The Feeling is defined as mental symptoms that tend to be subjective that in general connected to knowing and experiencing symptoms with pleasure or not to various degrees [20]. A feeling, happiness, or not will always surround every activity and experience. The passion, in general, is connected with knowing function that means feeling can occur because of observation, assuming, remembering, or considering something. The feeling is referred to as feeling pleasure and attracted. Feeling was a psychic activity that inside it can be found appreciating the value of a particular object [22]. 
Feeling as a non-intellectual psychic factor that mainly affects passion for studying. If a student conducts a little bit spontaneous assessment through their feeling about the learning experience in school, and that assessment was resulting in a positive outcome, then that will produce a pleasant feeling, but if the result is negative then will cause an unpleasant feeling. Pleasure feeling can create a desire that strengthened by a positive gesture. Meanwhile, uncomfortable feelings can slow the learning process because there is no positive gesture that did not attract the willingness to learn.

\subsubsection{Interest to subjects and teacher}

Not all students like some issues because of their interest in learning. There is some student that develop their interest to learn because of the teacher's influence, classmate, and exciting topics. In the long run, if the student can build their interest to learn the subjects, then they will succeed even though they are average students.

Lack of interest in a particular subject can because of why the pupil did not take notes that have been taught by the teacher. It is a sign that the student has a lack of motivation to learn. Because of that, the teacher should be able to raise student's motivation, so the students have their motivation to learn.

In the learning process, motivation is needed; that is why a person that were not motivated to learn will not make any learning activity. This is a sign that those activities will not touch their needs and everything that attracts interest to some person as long as those did not affect their needs. Because of that, what a particular person sees will raise their attention as long as it is related to their interests. So, motivation is a primary stimulus that boosts learning activity, so they have an interest in particular objects because the benefit is a motivation tool in learning.

\subsection{Student Perception}

According to Liu, Yoshino,\& Mochida perception, in short, means vision, how someone looks for something, whereas in extended means, how someone interprets and articulates something [23]. So \& Brush explain that perception is an object that captured and projected in the final part of the brain so that we could observe the object [24]. McDonald interpret that perception is someone observation that derived from their cognition component [25]. The cognition aspect is a transformation driving element since the information that goes through will determine the feeling and will to act. Therefore cognition component will react to someone's tendency to perform well or not toward something that forms an answer to question what has been considered or perceived about it.

Young \& Bruce said that perception involves in two work process that related to each other, first receive impression through vision, touch, and other senses; and second, analyze or interpret the meaning of reactions with definition structure (a relevant belief that emerges from experience) of someone with evaluative structure (values in someone beliefs) [26]. Perception is not an implicit process, because the response to a various assessment of senses sign could be happening below the consciousness threshold. Student perceptions are significant determinants of attempts to enhance higher education learning environments [27].

In this research, the perception will be emphasized to the idea point of view that being done by students to observe and respond to a problem. Therefore, need to be some understanding of the perception that aimed at this research.

\subsubsection{Fear of Negative Teacher Traits.}

Lecturer traits influence student confidence in classroom discussions. Tanveer stated, "Lots 
of past researchers mentioned that negative lecturer traits discourage students participation" [28]. A like from preceding studies, many student participation can be determined by negative lecturer traits such as being impatient and lack of teaching skills according to the present paper. A few of the components that play a role in student reluctance in classroom discussions participation are afraid of being humiliated and criticized in front of classmates. Thereupon, to stay away from any teacher humiliation and criticism, the students would rather stay silent. This outcome is in line with Tanveer who discover that student limitation to the new language will influence student reluctance in the classroom [28].

\subsubsection{Student fear of Being Laughed and Making Mistake}

Fear of making errors is frequently quoted as another source of passivity and reluctance, and this uneasiness is connected to some Eastern culture aspects such as a requirement to be as perfect as possible and fear of embarrassment [29]. The result of this study matched with this respect too. The participants often express the fear of making errors or mistakes in front of their classmates. The feeling of being incompetent makes them anxious.

\subsubsection{Shyness}

Shyness was another affecting calculate which might influence students' support. Shyness can be seen as a problem for impression management and low self-efficacy beliefs about the social success of one[30]. In any case, shyness, agreeing to Zee \& Roorda shyness usually refers to the trepidation and wariness of students in the face of new conditions [31]. Juhana said that speaking in front of other people is one of the more common fears that students experience and feeling of shyness makes their mind go blank or that they will disregard what they need to say some time recently[29]. Shy students are likely to doubt and worry about new persons, activities, and conditions, and may feel self-conscious or even humiliated when they feel like they are being socially assessed [32]. Shyness is an enthusiastic thing that confronted by many students when they are inquired to speak English in front of the class.

\subsubsection{Fear of Being Volunteered to Answer or Ask a Question in Class}

One of the problems encountered by learners is being frightened to speak due to fear of making mistakes. The participants are asked about how they feel about answering and asking the question during the learning process, and a third and more stated that during class, they are frequently afraid of requesting the problem to the lecturer. This is equivalent to $\mathrm{Wu}$ that proclaim that "the learners in their studies get anxious on the off chance that they raise comments and questions amid English class" [33].

\subsubsection{Fear of Negative Teacher Evaluation}

The current study discovers that the source of anxiety in English as a Foreign Language classroom is fear of negative evaluation. The student is concerned because they cannot speak English good enough. Students think that the lecturer will evaluate them negatively if they make a mistake; therefore, they will remain silent, and this perception is very likely due to teaching and practice the teacher employs 


\section{Method}

The researcher applied qualitative method which include 10 EFL students who join EFL class subject and have several attendances in the English classroom. This is the ideal number of participants is around 6-10. Further, the researcher used descriptive qualitative to describe the study on the real-life context in order to explore the obstacles faced by the participants.

Further, the data collection was done through a semi-structured interview. This method allows the interviewer to have structured guidance in hand. In line with this, semi-structure interview is particularly appropriate if the researcher has been familiar with the context and phenomenon and does not want to use ready-made response categories that would limit the depth and breadth of the respondents' story. After interviewing, the audio was converted into written data via the transcription process, and the data were translated into full English. Regarding the issue of transcription, first process involved reading the raw transcriptional that consist of many pages. After that, the text transcription was being split up into smaller segments to help the researcher to identify or underline the new information related to the topic.

\section{Results and Discussion}

This research is putting some main factor that affects students' participation in EFL classroom, such as linguistic factors, psycholinguistic factors, socio-cultural factors, institutional factors. For the further information, the researcher quoted the information gained from participant and provide the explanation with related literature and studies to support the participants' explanation.

\subsection{Linguistic Factors}

It occasionally influence students' participation in classroom activities. The participant stated that the difficulties in utilizing proper grammar, lack of vocabulary, pronouncing English words, and another sort of thing which makes participants reluctant and unwilling to speak or to participate in English classroom. Lack of language structure. The student concedes that they have learned grammar for a long time since they are in primary school until they become a university students. This issue constrains them to talk fluently in English.

"I can't talk English fluently because the problem confront when talking English is I don't get it the structure used in some cases. It makes me clear that I overlooked what I need to say before." (S1)

Lack of vocabulary. This revealed as the other issue that experienced by the students in speaking English. The students stated that they cannot express their thoughts and opinion since they have limited vocabularies. They don't know how to say their words in English well.

"I do not have more words to talk and express the limited words makes me difficult to precise my own words in English. It makes me troublesome to talk in English". (S2) 
Lack of pronouncing English words. Another reason why students are unwillingness to participate in EFL classroom is because they cannot pronounce the words and sentence correctly. They cannot express the divine word to communicate with each other in English.

"When I talk or speak some student are confused about what I pronounce because I failed to say it, and sometimes they laughed at." (S3)

Low participation in classroom activities. The students are afraid to talk and participate in the classroom because of grammar things and limited of words. They don't get a specific mind and understand the language structure in the right way. It makes them noiseless in the EFL Classroom. They fear in volunteering to ask or answer the questions.

\subsection{Psycholinguistic Factors}

The second factor that affects the participant's reluctance to communicate in English is shyness and uneasy feeling. Student sometimes feels shyness when they talk each other in the classroom, and they felt shyness because the student has lack of things in English and makes student afraid to do conversation in English and the impact to student participation in a class, they thought uneasy to talk English as well.

"I felt afraid, and it makes me shyness to talk with other students when I try to talk in English in the class." (S4)

"I afraid that another student will judge me when I talk in English."(S5)

"I shyness to talk with my friend. I afraid if they are laughing when I make a mistake."(S6)

The participants admit that the student was afraid to make a mistake, and it makes them a bit shy though it was reasonable to make a mistake, especially when learning a new language. All of the participants admit that they are afraid of being judged as 'showing-off' or 'arrogant' when trying to speak English with their friends. They all confessed when they try to communicate in English with friends get haunted with that kind of uneasy feeling.

\subsection{Socio-cultural Factor}

The third factor is the socio-cultural factor that affects the participants' to communicate in English. The participants are Indonesian and they came from different culture which makes them tend to use their native language most of the time. The participants feel it demotivated to communicate in English because most of their friends were using their native language or Bahasa Daerah, and that kind of habit influenced the reluctance to communicate in English. In brief, the three participants admitted this kind of situation.

"Sometimes, when I try to talk English with my friends and try to practice in daily activity, but ma friends sometimes give a response with Bahasa or Bahasa Daerah (the same hometown)"(S7)

"I made rules with my friends to always talk in English when we are taught, but they almost use Bahasa to respond and when I can practice English directly? No more way to me to fluent in spoken English" (S8) 


\subsection{Institutional Factors}

The fourth factor that affected participant reluctant to communicate in English and participate in EFL classroom is caused by institutional factors such as the lecturer's teaching method and institution's rules that were strict and ambiguous. There are no rigid and clear rules during learning and teaching time that oblige all of the students and lecturers to speak English regularly. Besides, there was no punishment for those who violate the rules. The participants also stated that some lecturers still utilize lecturer-oriented teaching methods which means that the lecturer is more active than the students.

"Teacher sometime just explain the subject of study in front of class without give a change students to respond" (S5)

Furthermore, one of the participants confessed that when students communicate in English, particular lecturers tend to criticize them. This will prevent the students to communicate regularly in English.

Ifeel bad when I try to response the teacher explanations using English, ma teacher cut off ma question in one way and teachers say that my English so bad"'(S9)"

"Teacher explain the object of study, after that teacher give a question, and I try to answer the question and present the re-explanation the subject in front of the class, I use English and missed some vocabulary and structure, you know what happens to me? My score is C, I don't wanna answer the question anymore" (S10)"

Moreover, another participant claimed that lecturers are inconsistent when comes it comes to provide a good model for students, such as when the student asks a question in Bahasa, then the lecturer proceeds to follow the student to answer in Bahasa. As a good role model, the lecturers should always speak in English although students still use Bahasa. The participants agreed that institutional factors are one of the most influential factors affecting their unwillingness to communicate more often in English.

This research has discovered some factors that caused students unwilling to participate in EFL classroom. It was found that some of the students are fear of negative teacher traits, and fear of negative teacher evaluation, fear of teacher's judgment, fear of making mistakes and being laughed, and fear of volunteering to ask or answer a question. This resulted on student participation on English class which make them absent for many times.

This study has explored the the students' perception toward the unwillingness to participate in EFL class subject that encountered graduate students at Universitas Ahmad Dahlan. The most problems faced by the students are fear of negative teacher traits, fear of making mistakes and being laughed at, fear of volunteering to ask or answer a question and fear of negative teacher evaluation.In this current research, the student unwillingness in EFL subject are influenced by Linguistics Factor, Psycholinguistic Factors, Socio-cultural Factors, and Institutional Factors. The Linguistics factor such as lack of language structure, lack of vocabulary, lack of pronouncing English words, low participation in classroom activities. a linguistic factor such as. psycholinguistic factors like Shyness and uneasy feelings, socio-cultural factors that consist a culture and mother tongue, student feels the mother tongue one of the reasons that can choke of student unwillingness to participate or communication in English, and institutional factor, this factor are about a teacher or lecturer's method of teaching and institution's rules the that 
were strict way rules.

These results are in line with the previous study that student feel unwillingness conclude by Savaşçi the findings showed that several factors such as anxiety, fear of being despised, teacher strategy, and culture have been found to affect the problem of reluctance between speakers [7]. Another researchers' findings also line with the current study. Herriansyah and Nakhah studies' findings showed that the students not confidence to speak, fear of mistakes, anxiety, shyness, low participation in speaking class are the problems in speaking area[8][9].. However, another resarch was found that the personality characteristics of the teacher, the communication skills of students, the learning atmosphere, the motivation of students, self-confidence and topical information, and interesting discussion topics play important roles in the involvement of students in the oral class in English[11][12][13]. Mofareh explain that a general weakness in English grammar, vocabulary, syntax, poor fluency in speech, poor understanding of general grammar frameworks, and inaccurate pronunciation were attributed to the percentages varying between average, weak, and very weak[10]. So, it can be said that the most influence factors student feel unwillingness in class based in this below; linguistic factors, psycholinguistic factors, socio-cultural factors, and institutional that factor. Result get more the impact of student to participate in classroom such as; fear of negative teacher traits, fear of making mistakes and being laughed at, shyness, fear of volunteering to ask or answer a question in class and fear of negative teacher evaluation.

In other word, most of students were shown to have a strong unwillingness to take a part on communication using English with the other one. This indicated that most of them had a problem to use the English language in the classroom that impact in their participation to join the class. More importantly, they did not seem to enjoy the whole communication using English with their peers.

\section{Conclusion}

Based on the research findings and discussion above, the researcher got some conclusions concerning. Then, it could be concluded that the major factors which affected the participants to feel unwilling to communicate more often in English in classroom encountered by first semester students of English Education Department consist into four factors; linguistic factors, psycholinguistic factors, socio-cultural factors, and institutional that factor. The researcher divided the unwillingness student to participate in EFL classroom such as; fear of negative teacher traits, fear of making mistakes and being laughed at, shyness, fear of volunteering to ask or answer a question in class and fear of negative teacher evaluation. Some recommendations were suggested after performing the analysis. Communication skills are not stand-alone, but are accompanied by many things, such as learning vocabulary, grammar and pronunciation, the most important things we need to remember.

Psycholinguistic factors an important role in order to make the students confident and not afraid of making errors and mistake while they are required to communication in front of other people. The researcher suggest to the next researcher who interested to conduct the same case to gain more participants as the subject of the study. Future research will want to explore other 
potential explanations for unwillingness student to participate more in classes and include useful strategies to engage EFL students. There is, however, a need for further study in this field, involving more respondents. The lack of time and condition makes the researcher just take limited partipant in the first semester students of English Education in Ahmad Dahlan University as a subject in this study.

\section{References}

[1] Escobar Fandiño, Fredy Geovanni; Muñoz, Luz Dary; Silva Velandia, Angela Juliette (2019). Motivation and E-Learning English as a foreign language: A qualitative study. Heliyon, 5(9), e02394-. doi:10.1016/j.heliyon.2019.e02394

[2] Chien, Shu-Yun; Hwang, Gwo-Jen; Siu-Yung Jong, Morris (2019). Effects of peer assessment within the context of spherical video-based virtual reality on EFL students' English-Speaking performance and learning perceptions. Computers \& Education, (), 103751. doi:10.1016/j.compedu.2019.103751.

[3] Hu, Jingjing; Wu, Peng (2020). Understanding English language learning in tertiary Englishmedium instruction contexts in China. System, 102305- doi:10.1016/j.system.2020.102305

[4] MacIntyre P D, Dörnyei Z, Clément R and Noels K A 1998 Conceptualizing willingness to a L2: Communicate in confidence model situational Mod. Lang. J. 82 545-62

[5] Turner, J. E., Li, B., \& Wei, M. (2021). Exploring effects of culture on students' achievement motives and goals, self-efficacy, and willingness for public performances: The case of Chinese students' speaking English in class. Learning and Individual Differences, 85, 101943. doi:10.1016/j.lindif.2020.101943

[6] Freiermuth, Mark R.; Ito, Michiyo F. (2020). Seeking the source: The effect of personality and previous experiences on university students', L2 willingness to communicate. Learning and Motivation, 71(), 101640-. doi:10.1016/j.lmot.2020.101640

[7] Savaşç1, Merve (2014). Why are Some Students Reluctant to Use L2 in EFL Speaking Classes? An Action Research at Tertiary Level. Procedia - Social and Behavioral Sciences, 116(), 2682 2686. doi:10.1016/j.sbspro.2014.01.635

[8] Heriansyah, H. (2012). Speaking problems faced by the English department students of Syiah Kuala University. Lingua Didaktika: Jurnal Bahasa Dan Pembelajaran Bahasa, 6(1), 37-44

[9] Ahmed Maher Mahmoud Al Nakhalah. (2016). Problems and Difficulties of Speaking That Encounter English Language Students at Al Quds Open University. International Journal of Humanities and Social Science Invention, 5(12), 96-101.

[10] Mofareh A., Alqahtani (2019). Difficulties Facing Students in English Language Conversation. International Research in Higher Education, 4(3), 51-.doi:10.5430/irhe.v4n3p51

[11] Murad A I and Jalambo M O 2019 EFL Students' Reluctance in Participating in EnglishSpeaking Activities at University College of Applied Sciences: Challenges and Solutions Open J. Soc. Sci. 07 28-51

[12] Priyadarshani, D., \& Sharma, S. (2020). A study on communicative English in Teaching-learning process at the primary level. International Journal of Multidisciplinar. Volume-05 ISSN: 2455-3085

[13] Han, L., \& Yusof, M.A. (2019). Students' Self-reflections of Own Participation in English Language Oral Class. LSP International Journal,Vol.6,Issue 2,2019,79-92

[14] Erbeli, F., \& Joshi, R. M. (2020). Simple view of reading among Slovenian English foreign language learners: A latent interaction modeling approach. Learning and Individual Differences, 101958.

[15] Bhowmik, S.K., 2015. World Englishes and English language teaching: a pragmatic and humanistic approach. Colomb. Appl. Ling. J. 17 (1), 142-157

[16] Fryer, Luke K.; Thompson, Andrew; Nakao, Kaori; Howarth, Mark; Gallacher, Andrew (2020). Supporting self-efficacy beliefs and interest as educational inputs and outcomes: Framing 
AI and Human partnered task experiences. Learning and Individual Differences, 80(), 101850. doi:10.1016/j.lindif.2020.101850

[17] Sulaiman, S. 2019. A Correlational Study between Student'S English Interest, Vocabulary Mastery and Student's Achievement. Jurnal Pendidikan Bahasa, 8(1), 183.https://doi.org/10.31571/bahasa.v8i1.1144

[18] Fryer, Luke K.; Ainley, Mary (2017). Supporting interest in a study domain: A longitudinal test of the interplay between interest, utility-value, and competence beliefs. Learning and Instruction, (),S0959475217303171- doi:10.1016/j. learninstruc.2017.11.002

[19] Maslow, A.H. 2013Toward a Psychology of Being. Start Publishing LLC, New York

[20] Yun, M. R., Shin, N., Kim, H., Jang, I. S., Ha, M. J., \& Yu, B. (2020). Effects of school-based meditation courses on self-reflection, academic attention, and subjective well-being in South Korean middle school students. Journal of Pediatric Nursing. doi:10.1016/j.pedn.2020.05.002

[21] Parry, D. A., le Roux, D. B., \& Bantjes, J. R. (2019). Testing the feasibility of a media multitasking self-regulation intervention for students: Behaviour change, attention, and self-perception. Computers in Human Behavior, 106182. doi:10.1016/j.chb.2019.106182

[22] Bijleveld, E. (2018). The feeling of effort during mental activity. Consciousness and Cognition, 63, 218-227. doi:10.1016/j.concog.2018.05.013

[23] Liu, S., Yoshino, H., \& Mochida, A. (2011). A Measurement Study on the Indoor Climate of a College Classroom. International Journal of Ventilation, 10(3), 251261. doi:10.1080/14733315.2011.11683953

[24] So, H.-J., \& Brush, T. A. (2008). Student perceptions of collaborative learning, social presence and satisfaction in a blended learning environment: Relationships and critical factors. Computers \& Education, 51(1), 318-336. doi:10.1016/j.compedu.2007.05.00

[25] McDonald, S. M. (2012). Perception: A Concept Analysis. International Journal of Nursing Knowledge, 23(1), 2-9. doi:10.1111/j.2047-3095.2011.01198.x

[26] Young AW, Bruce V. Understanding person perception. Br J Psychol. 2011;102(4):959-974. doi:10.1111/j.2044-8295.2011.02045.x

[27] Yang, Z., Becerik-Gerber, B., \& Mino, L. (2013). A study on student perceptions of higher education classrooms: Impact of classroom attributes on student satisfaction and performance. Building and Environment, 70, 171-188. doi:10.1016/j.buildenv.2013.08.030

[28] Tanveer, M, 2007 Investigation of the factors that cause language anxiety for ESL / EFL learners in learning speaking skills and the influence it casts on communication in the target language. By $1-$ 92

[29] Juhana, J. (2012). Psychological Factors That Hinder Students from Speaking in English Class (A Case Study in a Senior High School in South Tangerang, Banten, Indonesia). Journal of Education and Practice, 3, 100-110.

[30] Oflaz, A. (2019). The effects of anxiety, shyness and language learning strategies on speaking skills and academic achievement. European Journal of Educational Research, 8(4), 999-1011. https://doi.org/10.12973/eu-jer.8.4.999

[31] Zee, M., \& Roorda, D. L. (2018). Student-teacher relationships in elementary school: The unique role of shyness, anxiety, and emotional problems. Learning and Individual Differences, 67, 156166. doi:10.1016/j.lindif.2018.08.006

[32] Crozier, W. R. (2001). Shyness, self-perception, and reticence. Self-perception: International perspectives on individual differences, 2, 53-76.

[33] Wu K 2010 The Relationship between Language Learners' Anxiety and Learning Strategy in the CLT Classrooms Int. Educ. Stud. 3 174-91 